\title{
A study on socio-demographic factors of alcoholics attending a deaddiction centre in Kannur district
}

\section{Mohandas B. ${ }^{1}$, Vivek S. ${ }^{2 *}$, Ratheesh R. ${ }^{3}$, Venugopalan P. P. ${ }^{4}$, Sarada A. K. ${ }^{5}$, Suprej K. ${ }^{6}$, Sobhith V. $\mathrm{K}^{7}$}

DOI: https://doi.org/10.17511/ijphr.2019.i5.01

1 Bindu Mohandas, Associate Professor, Department of Community Medicine, KMCT Medical College, Calicut, Kerala, India.

2* Vivek S., Associate Professor, Department of Community Medicine, Al-Azhar Medical College, Thodupuzha, Kerala, India.

3 Ratheesh R, Assistant Professor, Department of Pharmacology, KMCT Medical College, Calicut, Kerala, India.

${ }^{4}$ Venugopalan P. P., Former Professor \& HOD, Department of Community Medicine, Kannur Medical College, Anjarakandy, Kerala, India.

5 Sarada A. K., Former Professor \& HOD, Department of Community Medicine, Kannur Medical College, Anjarakandy, Kerala, India.

6 Suprej K, Statistical Assistant, All India Institute Of Medical Sciences, Delhi, India.

7 Sobhith V. K., Former Medical Social Worker, Department of Community Medicine, Kannur Medical College, Anjarakandy, Kerala, India.

Background: Alcoholism is a major public health problem in Kerala. It leads to serious social, mental and physical consequences. Method: A deaddiction centre based cross sectional study was done on 370 individuals using a predesigned questionnaire during the period of 2012-2013. The data was analyzed using SPSS version 17. Chi - Square test was used to find association between the study variables. Results: The study was done on 370 alcohol dependent subjects. The mean age of the study subjects was $38.08 \pm 8.46$ years. $64.3 \%$ of the study subjects were from rural areas. The mean age of starting alcohol consumption was $25.46 \pm 6.6$ years. Family history of alcohol consumption was present in $99(26.8 \%)$ patients. The age at initiation of alcohol intake was significantly $(p<0.05$ ) associated with family history. The mean duration of drinking was $12.62 \pm 7.47$ years. $42.4 \%$ of the study subjects consumed brandy. $37.6 \%$ of them consumed < $200 \mathrm{ml}$ of alcohol per day. Peer pressure was the most common reason cited by $44.1 \%$ individuals for starting alcohol consumption. The most common reason cited by $30.5 \%$ individuals for continuing alcohol consumption was because they liked its effect. Conclusion: Alcohol use is a serious public health problem. Awareness programs regarding its harmful use should be given to the people in the community.

Keywords: Alcohol, Deaddiction centre, Non communicable diseases

Corresponding Author

Vivek S., Associate Professor, Department of Community Medicine, Al-Azhar Medical College, Thodupuzha, Kerala, India.

Email: sat.panayil@gmail.com
How to Cite this Article

Mohandas B, Vivek S, Ratheesh R, Venugopalan PP, Sarada AK, Suprej K, Sobhith VK. A study on sociodemographic factors of alcoholics attending a deaddiction centre in Kannur district. Public Health Rev Int J Public Health Res. 2019;6(5):177-183. Available From

https://publichealth.medresearch.in/index.php/ijphr/ article/view/117

$\begin{array}{cc}\begin{array}{c}\text { Manuscript Received } \\ 2019-0920\end{array} & \begin{array}{c}\text { Review Round } 1 \\ 2019-09-30\end{array} \\ \text { Conflict of Interest } \\ \text { No } & \text { Funding } \\ \text { Nil }\end{array}$

\section{Review Round 2 2019-10-06 \\ thical Approval}




\section{Introduction}

Alcohol is considered as a social symbol for many in the population. But alcohol consumption contributes to 3 million deaths each year globally as well as to the disabilities and poor health of millions of people. Harmful use of alcohol is responsible for $5.1 \%$ of the global burden of disease. It is accountable for $7.1 \%$ and $2.2 \%$ of the global burden for males and females respectively [1]. Alcohol is a major risk factor for non communicable diseases (NCDs) including cancers and cardiovascular diseases, communicable diseases such as tuberculosis, HIV/AIDS, violence and injuries. Globally alcohol consumption is the seventh leading risk factor

For premature death and disability [2]. In India around $20-30 \%$ of adult males and $5 \%$ of females use alcohol. While alcohol is used traditionally by men, its use by women is now on the increase. Issues of concern include pay-day drinking, domestic violence, alcohol's contribution to poverty, illicit and home-brewed alcohol, and reduction in average age of initiation [3]. The health problems for which alcohol is responsible are only a part of the total social damage which includes family disorganization, crime and loss of productivity [4].

Alcohol abuse is one of the main killers of young men in India today. However, its real impact is on the social and family dynamics that underlie its communities. In India household expenditure on alcohol varies between $3 \%$ to $45 \%$ of income. Domestic violence and an exacerbation of poverty have made alcohol abuse the single most important problem for women in India. With one in three people in India falling below the poverty line, the economic consequences of expenditures on alcohol attain special significance.

Besides money spent on alcohol, a heavy drinker also suffers other adverse economic effects. These include reduced wages (because of missed work and lowered efficiency on the job), increased medical expenses for illness and accidents, legal cost of drink-related offences, and decreased eligibility of loans. Industry association sources estimate that $15 \%$ to $20 \%$ of absenteeism and $40 \%$ of accidents at work are due to alcohol. Alcohol use among industrial workers is increasing and this has led to an increase in alcohol-related sickness and absenteeism. The annual loss due to alcohol-related problems in workplaces is between Rs 70 000to 80 000 million.
Hazardous drinking in a male industrial worker population is significantly associated with severe health problems, such as head injuries and hospitalizations. Also, the country's road research institute estimates that $25 \%$ of road accidents are alcohol-related, one third of the drivers on the highway are under the influence of alcohol and $20 \%$ of accident-related head injury victims seen in emergency rooms of hospitals have consumed alcohol prior to the accident. Alcohol involvement is known to be present among $15 \%$ to $20 \%$ of traumatic brain injuries at the time of injury [5].

The National Household Survey in India reported that, of the 62.5 million alcohol-users in India, 10.6 million are dependent users [6]. Kerala consumes more alcohol than any other state in India. Per capita consumption of alcohol in Kerala (in 2010) is 11.1 liters/person /year [7]. Alcohol misuse is a major cause of morbidity and mortality and an important health care burden. In the view of this background the present study was conducted to study the socio demographic characteristics and factors for alcoholism in alcoholic patients attending a deaddiction centre of Thalassery, Kannur district.

\section{Materials and methods}

Setting: Deaddiction centre, Thalassery, Kannur

Duration: 2012-2013

Type of study: Cross sectional study

Sampling method: Convenient sampling

Sample size calculation: A total sample of 370 individuals was obtained using the $21.4 \%$ prevalence of alcohol consumption in study done by Gururaj et al [8]. Sample size was calculated using the formula $n=4 p q / L 2$, where $n=$ required sample size, $p=$ approximate prevalence rate from previous study, $q=1-p$, and $L=$ permissible error in the estimate of $p$ [9].

$\mathrm{P}=21.4 \%, \mathrm{q}=78.6 \%, \mathrm{~L}=20 \%$ of $\mathrm{p}=4.28$; substituting the values in the above formula,

$\mathrm{N}=(4 \times 21.4 \times 78.6) /(4.28) 2=367.28$ rounded to 370 .

\section{Inclusion criteria}

01. Patients who fulfill the ICD-10 criteria for alcohol dependence according to the ICD-10 classification of mental and behavioral disorders: clinical descriptions and diagnostic guidelines. 
02. Patients who give consent to participate in the study.

Exclusion criteria: Patients with co-morbidities like psychiatric illnesses, multiple substance dependence, hypertension, diabetes mellitus, asthma and stroke.

Data collection procedure: Data was collected using a self structured questionnaire which contained name, age, domicile status, education, occupation, income, marital status, type of alcohol consumed, quantity of alcohol consumption, duration of alcohol consumption, family history of alcohol consumption, reasons for starting, continuing, and wanting to stop alcohol consumption.

Modified B J Prasad's classification was used to assess the socio-economic status of the patients studied [10].

International Classification of Diseases tenth revision (ICD 10) was used for defining criteria of alcohol dependence [11]. Alcohol dependent patients who were admitted to the deaddiction centre, who fulfilled the inclusion criteria for alcohol dependence according to the ICD-10 classification of mental and behavioral disorders: clinical descriptions and diagnostic guidelines; and who gave written informed consent were recruited for the study.

Data analysis: The data was entered in Microsoft Excel and analyzed using SPSS version 17. Chi Square test was used to find association between the study variables. A $p$-value of $<0.05$ was considered significant for the study.

Ethical consideration and permission: The study was conducted after obtaining the approval from the Institutional Ethics Committee and permission was sought from the authority of the Thalassery deaddiction centre.

\section{Results}

Out of the 370 male patients studied, the age of the study subjects ranged from 18 to 63 years. The mean age of the study subjects was $38.08 \pm 8.46$ years. The socio demographic details of the study participants are depicted in Table. 1

Table-1: Socio demographic characteristics of study participants $(n=370)$.

\begin{tabular}{|l|l|l|}
\hline Socio demographic variables & Number $(n=370)$ & Percentage (\%) \\
\hline
\end{tabular} Residence

\begin{tabular}{|c|c|c|}
\hline Rural & 238 & 64.3 \\
\hline Urban & 132 & 35.7 \\
\hline \multicolumn{3}{|l|}{ Religion } \\
\hline Hindu & 214 & 57.84 \\
\hline Muslim & 44 & 11.89 \\
\hline Christian & 112 & 30.27 \\
\hline \multicolumn{3}{|l|}{ Education } \\
\hline Professional degree & 10 & 2.7 \\
\hline Postgraduate/Graduate & 77 & 20.8 \\
\hline Pre degree & 77 & 20.8 \\
\hline High school & 161 & 43.5 \\
\hline Middle school & 42 & 11.4 \\
\hline Primary school & 3 & 0.8 \\
\hline \multicolumn{3}{|l|}{ Occupation } \\
\hline Professional & 10 & 2.7 \\
\hline Semi professional & 2 & 0.5 \\
\hline Clerk/shop owner/agriculture & 153 & 41.4 \\
\hline Skilled & 84 & 22.7 \\
\hline Semi-skilled & 37 & 10 \\
\hline Unskilled & 77 & 20.8 \\
\hline Students & 7 & 1.9 \\
\hline \multicolumn{3}{|l|}{ Socioeconomic status } \\
\hline Class I & 37 & 10 \\
\hline Class II & 232 & 62.7 \\
\hline Class III & 96 & 25.9 \\
\hline Class IV & 5 & 1.4 \\
\hline Class $\mathrm{V}$ & 0 & 0 \\
\hline \multicolumn{3}{|l|}{ Marital status } \\
\hline Married & 281 & 75.9 \\
\hline Unmarried & 71 & 19.2 \\
\hline Separated & 11 & 3 \\
\hline Divorced & 3 & 0.8 \\
\hline Widower & 4 & 1.1 \\
\hline
\end{tabular}

The mean age of starting alcohol consumption was $25.46 \pm 6.6$ years. The mean duration of drinking was $12.62 \pm 7.47$ years. Alcohol consumption characteristics of the study participants are depicted in Table 2. Family history of alcohol consumption was present in $99(26.76 \%)$ patients. The age at initiation of alcohol intake was significantly ( $p=$ 0.005 ) associated with family history as shown in Table 3.

Table-2: Alcohol consumption characteristics of the study participants

\begin{tabular}{|l|l|l|}
\hline \multicolumn{1}{|c|}{ Variables } & Number $(\mathrm{n}=\mathbf{3 7 0})$ & Percentage (\%) \\
\hline Family history of alcohol consumption \\
\hline Yes & 99 & 22.76 \\
\hline No & 271 & 73.24 \\
\hline Time of 1st drink of the day \\
\hline Morning & 12 & 3.2 \\
\hline
\end{tabular}




\begin{tabular}{|c|c|c|}
\hline Afternoon & 10 & 2.7 \\
\hline Evening & 115 & 31.1 \\
\hline Night & 108 & 29.2 \\
\hline No specific time & 125 & 33.8 \\
\hline \multicolumn{3}{|l|}{ Type of alcohol } \\
\hline Brandy & 157 & 42.4 \\
\hline Toddy & 75 & 20.3 \\
\hline Rum & 73 & 19.7 \\
\hline Whisky & 53 & 14.3 \\
\hline Beer & 9 & 2.4 \\
\hline Vodka & 3 & 0.8 \\
\hline \multicolumn{3}{|c|}{ Average quantity of alcohol consumption per day } \\
\hline$<200 \mathrm{ml}$ & 139 & 37.6 \\
\hline 200-399 ml & 107 & 28.9 \\
\hline $400-599 \mathrm{ml}$ & 2 & 0.5 \\
\hline $600-799 \mathrm{ml}$ & 82 & 22.2 \\
\hline$\geq 800 \mathrm{ml}$ & 40 & 10.8 \\
\hline \multicolumn{3}{|c|}{ Reasons for starting alcohol consumption } \\
\hline Peer pressure & 163 & 44.1 \\
\hline Experimentation/ curiosity & 47 & 12.7 \\
\hline Feel of strength \& to work more & 44 & 11.4 \\
\hline Relief from tension & 37 & 37 \\
\hline Seeing father/ relatives & 29 & 29 \\
\hline Family problems & 28 & 28 \\
\hline Show off & 15 & 15 \\
\hline Love failure & 7 & 7 \\
\hline \multicolumn{3}{|c|}{ Reason for continuing alcohol consumption } \\
\hline Liked the effect of alcohol & 113 & 30.5 \\
\hline Tension relief & 62 & 16.8 \\
\hline Energy to work & 57 & 15.4 \\
\hline Merry making & 36 & 9.7 \\
\hline Relaxation & 30 & 8.1 \\
\hline Boost confidence & 29 & 7.8 \\
\hline Maintain social status & 18 & 4.9 \\
\hline Withdrawal symptoms & 17 & 4.6 \\
\hline Show off & 8 & 2.2 \\
\hline
\end{tabular}

Table-3: Distribution of patients according to family history of alcoholism and age at initiation of alcoholism.

\begin{tabular}{|l|l|l|}
\hline \multirow{2}{*}{ Age at initiation in years } & \multicolumn{2}{|l|}{ Family history of alcohol consumption } \\
\cline { 2 - 3 } & Present & Absent \\
\hline$<20$ & 23 & 54 \\
\hline $20-29$ & 62 & 133 \\
\hline$>30$ & 14 & 84 \\
\hline Total & 99 & 271 \\
\hline $\mathrm{X} 2=10.684, \mathrm{df}=2, \mathrm{p}=0.005$ & \\
\hline
\end{tabular}

$181(48.9 \%)$ of the study subjects spent $\leq$ Rs. 100 per day, followed by 98 (26.5\%) spent Rs. 101-200 per day, $66(17.8 \%)$ spent Rs. 201-300 per day, and $24(6.5 \%)$ spent $>$ Rs. 300 per day for alcohol consumption.
$298(80.5 \%)$ of the study subjects were aware that excessive alcohol consumption was harmful to health. The mean duration of drinking was $12.62 \pm 7.47$ years. Out of the 370 study subjects only $174(47 \%)$ knew about the availability of treatment for alcoholism.

$123(33.2 \%)$ of the study subjects wanted to stop alcohol consumption due to fear of losing wife and children, becoming aware of the family responsibilities or to avoid isolation from family members due to their drinking habit; followed by financial problems in $80(21.6 \%)$, problems at work place in $52(14.1 \%)$, compulsion by family members or friends in $45(12.2 \%)$, health problems in 44 $(11.9 \%)$, rejection of marriage proposals in 12 $(3.2 \%)$, to maintain social status in $9(2.4 \%)$, and fear of setting a bad role model to their children in 5 $(1.4 \%)$ study subjects.

\section{Discussion}

Out of 370 study subjects studied, the least number of study subjects were from Muslim community (11.89\%). This may be because alcoholic drinks are tabooed in Muslim community [12]. $75.9 \%$ of the study participants in present study were married.43.5\% of them had high school education. $41.4 \%$ of them belonged to the occupational category of clerk/shop owner/ agricultural workers and $20 \%$ of them were unskilled workers. $62.7 \%$ of them belonged to Class II of Modified B J Prasad's classification.

In a hospital based study done by Sarkar AP et al $82.35 \%$ was married individuals. And in their study, majority of them $(45.99 \%)$ were having non-formal education and $55 \%$ were unskilled workers, only $28.34 \%$ were doing clerical jobs.

And $44.38 \%$ of the study participants in their study belonged to Class II of Modified B J Prasad's classification [13]. The mean age of starting alcohol consumption was $25.46 \pm 6.6$ years in the present study. But it was slightly lower in the study done by Pradeep RJ et al where it was $21.39 \pm 5.34$ years [14].

Out of 370 study subjects, $99(26.8 \%)$ had family history of alcohol consumption. Among them 62 $(62.6 \%)$ were in the age group of 20-29 years. When age of onset of drinking was analyzed in relation to family history, it was found that family history of alcohol consumption was significantly associated with age at initiation of drinking ( $p<$ 0.05). 
The finding of this study is in agreement with the findings of Sarkar AP et al [13] and Pradeep RJ et al [14]. The most common type of alcohol consumed by the study subjects in the present study was brandy, followed by toddy. In a study by Gururaj G et al the most common type of alcohol consumed was whisky, followed by arrack [8].

In both these studies, local drink was the second most favoured drink. This may be due to the easy availability of the local drink in Kerala as elsewhere in India. But in the study done by Meena et al $69.07 \%$ of the individuals consumed country liquor followed by English liquor in $10.9 \%$ of the study participants [15].

The most common reason for starting alcohol consumption in the present study was peer pressure $44.1 \%$, followed by experimentation $12.7 \%$, feel of strength \& to work more $11.4 \%$, relief from tension $37 \%$, seeing father or relatives $29 \%$, family problems $28 \%$, show off $15 \%$ and love failure $7 \%$.

But in a study done by Girish N et al, $52 \%$ of then consumed alcohol to alleviate pain and to induce sleep, followed by peer pressure $48 \%$, habituation $45 \%$, family problems $20 \%$, financial problems $20 \%$, and pleasure seeking $20 \%$ [16].

$30.5 \%$ of the individuals in the present study said that the reason for continuing alcohol consumption was because the liked the effect of alcohol, $16.78 \%$ for tension relief, $15.4 \%$ for getting energy to work, merry making in $9.7 \%, 8.1 \%$ for relaxation, boosting confidence in $7.8 \%, 4.9 \%$ for maintaining social status, $4.6 \%$ due to withdrawal symptoms and $2.2 \%$ for to show off.

But in the study done by Girish $\mathrm{N}$ et al the most common reason to continue alcohol consumption was peer pressure in $67 \%$ followed by habituation in $57 \%$ of the individuals they studied [16].

$33.2 \%$ of the study subjects in the present study wanted to stop alcohol consumption due to fear of losing wife and children, becoming aware of the family responsibilities or to avoid isolation from family members due to their drinking habit; followed by financial problems in $21.6 \%$, problems at work place in $14.1 \%$, compulsion by family members or friends in $12.2 \%$, health problems in $11.9 \%$, rejection of marriage proposals in $3.2 \%$, to maintain social status in $2.4 \%$, and fear of setting a bad role model to their children in $1.4 \%$ study subjects.
But in a study done by Vignesh BT et al results showed that $100 \%$ of the individuals reported that family support was the biggest motivation for them to quit alcohol use. Health $(60 \%)$ was the second most important motivating factor for individuals to quit alcohol. Other motivations included access to better surroundings or environment $(27 \%)$, or by increasing the costs of alcohol purchases (16\%) [17].

Only $47 \%$ of the study subjects had the knowledge about deaddiction services. The study highlights the need for creating awareness among the public regarding the availability of treatment of alcoholism.

The deaddiction services should be made accessible and affordable to the people.

There is greater need for involvement of doctors and allied health professionals including health policy-makers for organization and delivery of programmes in the areas of early identification of problems, prevention of harm from alcohol use, treatment and rehabilitation.

Integration of deaddiction services into the primary health care system will help to deal with the problem. Alcohol anonymous groups to be established, consisting of ex-addicts, who encourage those who want to give up the habit of taking alcohol. There were several limitations in the present study. First it included a smaller sample from a single institution, and design adopted was cross sectional. Also the study was limited to one geographical location so the results of the study cannot be generalized.

\section{Conclusion}

Alcohol misuse not only affects the health of the individual but also his family relationships. Also it leads to social problems, economic instability in the family and majority of the study participants were unaware about the deaddiction services.

\section{What this study adds to the existing knowledge}

Alcohol abuse is a major public health problem, a programme for increasing awareness about the hazards related to alcohol use among the members of the general community is urgently required, and it should also include the availability of deaddiction services. 


\section{Author's contributions}

Dr. Bindu Mohandas: Concept, design, literature review, data collection, analysis, manuscript preparation \& editing.

Dr. Vivek S.: Concept, literature review, manuscript preparation \& editing.

Dr. R Ratheesh: Literature review, data collection, manuscript preparation \& editing.

Dr. P. P. Venugopalan: Concept, design, literature review.

Dr. A K Sarada: Concept, literature review.

Mr. Suprej K.: Design, analysis

Mr. Sobhith V. K.: Design, analysis

\section{Reference}

01. Alcohol.

Available at [Article] [Crossref]

02. WHO launches SAFER alcohol control initiative to prevent and reduce alcohol-related death and disability.

Available at: [Article] [Crossref]

03. WHO. Health situation in South East Asia Region. 2001-2007.

Available at: [Article] [Crossref]

04. Park K. Nutrition and Health, Park's Textbook of Preventive and Social Medicine. Banarsidas Bhanot Publishers. 2017;1167;561-617. [Crossref]

05. Ranaweera S. Current information on use and harm from alcohol in the WHO South East Asia Region. Alcohol control series No- 6, WHO Press. 2007.

Available at: [Article] [Crossref]

06. Gururaj G, Girish N, Benegal V, Chandra V, Pandav R. Public health problems caused by harmful use of alcohol- gaining less or losing more? (Alcohol control series No-2). New DelhiMacro Graphics Pvt Ltd. 2006; p-9-10.

[Crossref]

07. Alcoholic beverages consumed in Kerala. 2010. . [Crossref] [PubMed] [Google Scholar] [Crossref]
08. Gururaj G, Girish N, Benegal V, Chandra V, Pandav R. Burden and socioeconomic impact of alcohol, The Bangalore Study. World Health Organization, South East Asia Regional office, New Delhi. 2006.

[Crossref]

09. Suryakantha AH. Biostatistics Community Medicine (With Recent Advances). New DelhiJaypee Brothers Medical Publishers (P) Ltd. $2009 ; p-628$.

[Crossref]

10. Dudala SR, Arlappa N. An updated Prasad's socioeconomic status classification for 2013. Int J Res Dev Health. 2013;1(2)26-28.

[Crossref]

11. The ICD-10 Classification of Mental and Behavioural Disorders- Clinical descriptions and diagnostic guidelines. Available at:

[Article] [Crossref]

12. Saxena S. Country profile alcohol India, InLeanne Riley, Mac Marshall, Alcohol and public health in eight developing countries. WHO Geneva- Substance abuse department social change and mental health. 1999. Available at: [Article] [Crossref]

13. Sarkar AP, Sen $S$, Mondal $S$, Singh OP, Chakraborty A, Swaika B. A study on sociodemographic characteristics of alcoholics attending the de-addiction center at Burdwan medical college and hospital in West Bengal. Indian J Public Health. 2013;57(1)33-35. doi: 10.4103/0019-557X.111366 [Crossref]

14. Pradeep RJ, Banu S, Ashok MV. Severity of alcoholism in Indian males correlation with age of onset and family history of alcoholism. Indian J Psychiatry. 2010;52(3)243-249. doi: 10.4103/0019-5545. 70977 [Crossref]

15. Meena PK, Vohra AK, Rajput R. Prevalence and pattern of alcohol and substance abuse in urban areas of Rohtak city. Ind J Psychiat. 2002;44(4)348-352.

[Crossref]

16. Girish N, Kavita R, Gururaj G, Benegal V. Alcohol use and implications for public health patterns of use in four communities. Indian J Comm Med- Indian Association of Prevent Social Medi. $2010 ; 35(2) 238$. doi: $10.4103 / 0970-0218.66875$ [Crossref] 
17. Vignesh BT, Singh AK, Mohan SK, Murthy $S$, Joshi A. Association between sociodemographics and alcohol dependence among individuals living in an Indian setting. Global J Health Sci. 2014;6(3)16-26.

doi: $10.5539 /$ gjhs.v6n3p16 [Crossref] 